\title{
Gradient of strength and microstructure after deformation by free torsion of metal bar
}

\author{
A. P. Zhilyaev ${ }^{1,2}$, A. G. Raab ${ }^{\dagger, 1,3}$, G. I. Raab ${ }^{1,3}$, I.S. Kodirov ${ }^{3}$ \\ †agraab@mail.ru \\ ${ }^{1}$ Magnitogorsk State Technical University n. a. G. I. Nosov, 38 Lenin St., Magnitogorsk, 455000, Russia \\ ${ }^{2}$ Institute for Metals Superplasticity Problems RAS, 39 S. Khalturin St., Ufa, 450001, Russia \\ ${ }^{3}$ Institute of Physics of Advanced Materials, Ufa State Aviation Technical University, 12 K. Marx St., Ufa, 450008, Russia
}

\begin{abstract}
The article presents the results of the study and analysis of the structure, properties and deformation parameters of a longlength bar of a circular cross-section from grade 10 steel obtained using severe plastic deformation (SPD) by free torsion at a temperature of $600^{\circ} \mathrm{C}$. Using computer simulations with Deform 3D software, the stress-strain state of the samples, including the distribution of accumulated strain, average stresses, and thermal field, are investigated. A physical experiment was carried out, the structure parameters and microhardness in the longitudinal section of the samples after deformation were investigated. It was shown that the free-torsion SPD method provided a non-uniform accumulation of ultrahigh strains up to 6 in long-length metal bars of a circular cross-section, the formation of a gradient type structure with a mean grain size from 1 to $7 \mu \mathrm{m}$ and with a gradient in mechanical properties. The effect of localization of deformation during uniform torsion of the workpiece was revealed, at the same time, the temperature of the bar during severe plastic deformation increased up to $230^{\circ} \mathrm{C}$. EBSD analysis revealed a gradient structure of steel specimens with a mean grain size of about $1 \mu \mathrm{m}$ near the surface area and $\sim 5 \mu \mathrm{m}$ near the central area.
\end{abstract}

Keywords: free torsion, severe plastic deformation, computer simulation, mechanical properties, gradient microstructure.

\section{Introduction}

The widely known methods of SPD, in contrast to traditional methods of metal forming, are aimed to form a microstructure with a grain size less than one micron, changing the phase composition and mechanical properties throughout the volume of the material being deformed [1-10]. As a rule, this leads to a significant increase in the strength characteristics of deformable materials by $1.5-3$ times. However, with an increase in strength, the ductility of the material decreases, which limits the area of structural use of hardened materials. Besides, multi-cycle machining and a complex deforming tool enhance the cost of produced materials with an increased level of mechanical properties [8]. Recently, as an alternative to bulk UFG materials, consideration has been given to obtaining gradient structural states that provide rather high strength and plastic characteristics in bulk materials. However, the methods for obtaining such materials are rather limited; of course, the known methods of surface hardening (processing by shot-peening, smoothing, etc.) can be attributed to them; however, the effect of such approaches to increase the strength is insignificant [11]. The "Draw with Shear" method should be considered as the most developed method for obtaining a gradient of the structure and at the same time increasing the mechanical properties based on the principles of SPD [12-16]. Although it also requires the creation of a special tool and multi-cycle processing to obtain a pronounced gradient structural state and a high level of properties. Therefore, in the present work, to create a strain gradient, structure and properties, the method of free torsion of workpieces at elevated temperatures and, correspondingly, increased technological ductility [17], which does not require a complex special tool, was used. The aim of the work was to identify patterns of formation of structures and mechanical properties depending on the deformation parameters of thermo-mechanical processing.

\section{Materials and methods}

Low-carbon steel grade 10 with the following chemical composition: C 0.121-Si 0.263-Mn 0.418-P 0.0046-S 0.0053$\mathrm{Cr}$ 0.037-Ni 0.023-Cu 0.042-Al0.014 (wt.\%) was used as material for study. The material in the initial state is characterized by a well-defined granular structure with an average grain size of about 15 microns. The initially calibrated rods with a diameter of $10 \mathrm{~mm}$ had a tensile strength of $\sim 460 \mathrm{MPa}$, a yield strength of $\sim 350 \mathrm{MPa}$ and an elongation to failure of $\sim 25 \%$. Fig. 1 depicts initial microstructure of steel bar prior straining by torsion.

Fig. 2 shows the free torsion scheme, which was used to deform circular samples with a diameter of $10 \mathrm{~mm}$ and a length of $250 \mathrm{~mm}$. Deformation processing was carried out at a temperature of $600^{\circ} \mathrm{C}$, which is close to the recrystallization threshold of grade 10 steel. A physical experiment was carried out using a lathe that secured both ends of the sample and then rotated it around the longitudinal axis at a 


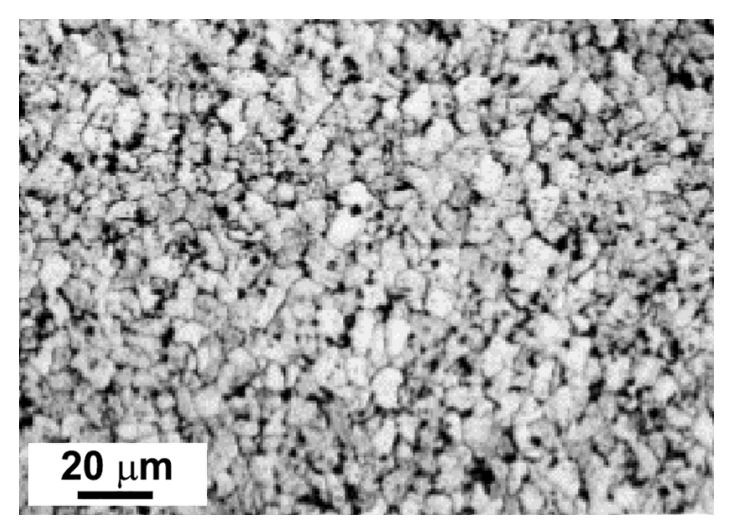

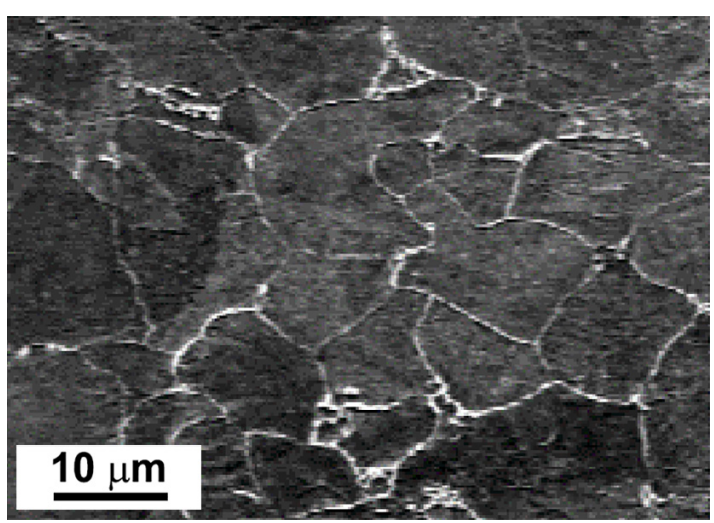

$\mathrm{b}$

Fig. 1. The microstructure of steel 10 in the initial state: light microscopy, $\times 500$ (a); scanning electron microscopy, $\times 2000$ (b).

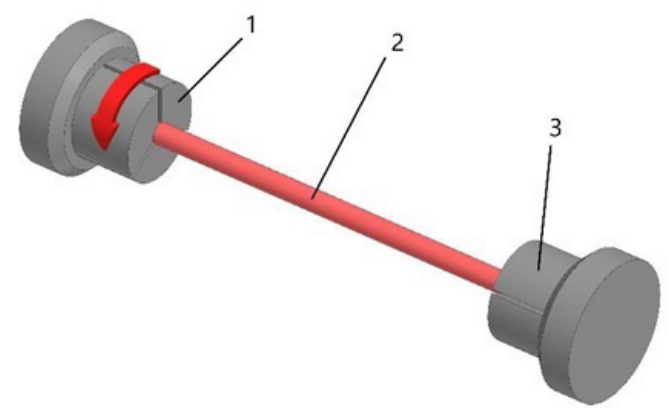

Fig. 2. Free torsion scheme: $1-$ movable clamp, $2-$ workpiece, 3 - fixed clamp.

constant speed of $12.5 \mathrm{rpm}$. The number of revolutions was fixed at the time of the failure of the workpiece, as a rule, this happened after 27 revolutions with the localization of the deformation zone. The computer simulation of the free torsion process was performed using the specialized software product "DEFORM-3D" [18], designed to solve metal forming problems. When modeling, the following boundary conditions were used: the number of elements of the workpiece grid 70000; the rotation speed of the movable gripper $12.5 \mathrm{rpm}$; the workpiece diameter $10 \mathrm{~mm}$. The length of the workpiece is $250 \mathrm{~mm}$. the number of revolutions is 27 . The material properties were used from the database of the software product for steel AISI1010.

The quantitative and qualitative analysis of the structure of the studied material is carried out on an OLYMPUS GX51 metallographic optical microscope. The electron microscopy studies were performed on a JEM-2100 transmission electron microscope. The average grain/sub-grain value was determined according to GOST 21073.3-75 by the method of crossing grain boundaries. The tensile tests to determine the characteristics of mechanical properties in the initial and fine-grained states were carried out on standard samples with a diameter of $3 \mathrm{~mm}$ with a base length of $15 \mathrm{~mm}$ at room temperature with a constant deformation rate of $1 \mathrm{~mm} / \mathrm{min}$ using an Instron 8862 machine, the maximum error for sample sizes is $0.02 \mathrm{~mm}$. The Vickers hardness (HV) was measured using a Micromet-5101 microindention tester with a load of $100 \mathrm{~g}$ for $15 \mathrm{~s}$. The number of measurements of each sample was at least 15 . The misorientation of grain boundaries was studied by electron backscattered diffraction (EBSD) [19].

\section{Results and discussion}

\subsection{Computer simulation of the free torsion}

As a result of computer simulation of the free-torsion scheme of a cylindrical steel sample in the Deform 3D software product, pictures and graphs of the distribution of the accumulated strain intensity and average stresses, patterns of temperature fields and microstructure in the longitudinal section of the workpiece were obtained, and the results were analyzed.

\subsubsection{Investigation of the deformed state}

The analysis of the obtained computer patterns of the deformed state of the sample after free torsion shows that when the deformation zone is localized in the surface layers, the degree of accumulated strain is $e=5.91$ (Fig. 3), and in the central layers on the longitudinal axis of rotation (symmetry) $e=2.8$, and there is a sequential increase in strain from the center of the workpiece to its periphery. The gradient accumulation of strain during torsion of a circular cross-section corresponds to the theoretical and graphical representation of the deformed state of this section [1], however, an important difference is that a rather high strain value $e=2.8$ is accumulated in the region of the axis of rotation (symmetry) of the localized deformation center, although theoretically, it should be equal to 0 . This, apparently, is associated with the influence of strongly deformed peripheral regions, for example, as with HPT $[1,3]$, on the central regions in the deformation zone. Along the length of the workpiece in the transverse direction, the gradient character of strain accumulation is preserved with a decrease in values, so it is closer to the fixation points of the workpiece on the surface $e=0.5$, and on the axis of symmetry $e \sim 0$.

The distribution diagram of the accumulated strain intensity in the cross-section of a localized deformation zone has a parabolic shape (Fig. $3 \mathrm{~b}$ ), which indicates the gradient of the deformed state. The strain distribution graph on the longitudinal axis of symmetry of the workpiece has an extremum in the region of localization of the deformation zone and is symmetrical with respect to the clamps. 


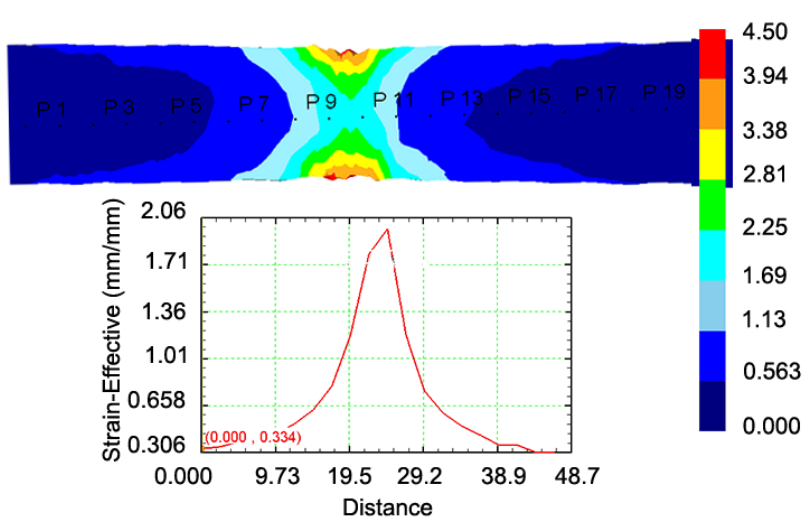

a

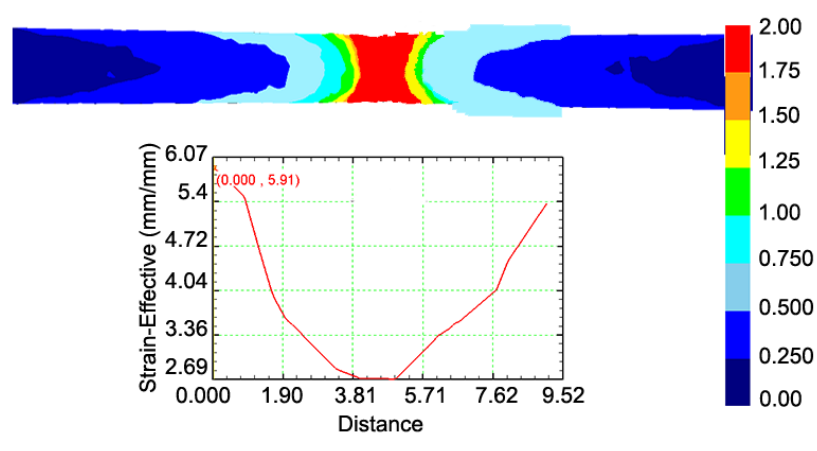

b

Fig. 3. (Color online) Picture and graphs of the distribution of the intensity of accumulated strain in the longitudinal (a) and transverse (b) sections.

\subsubsection{Investigation of the stress state}

According to computer simulation, the analysis of the distribution of average stresses by volume of the sample in the process of free torsion is carried out. As is known, the level of average tensile stresses affects the probability of the formation of defects and fractures during plastic deformation especially when exceeding the permissible values. From the obtained graphs and patterns of the distribution of average stresses, areas of compressive and tensile stresses were identified. The maximum compressive stresses are observed in the central region and reach values up to $76 \mathrm{MPa}$, while tensile stresses are observed in the surface region of the deformed sample and reach values up to $70 \mathrm{MPa}$, i. e. after 27 revolutions (at the time of fracture), the maximum permissible values are reached. It has been established that the magnitude of stresses increases with an increase in the level of accumulated strain; therefore, it is possible to predict and design the processing routes taking these values into account.

\subsubsection{Investigation of the effect of strain-induced heating}

As is known, any severe plastic deformation is accompanied by deformation heating. In this regard, the analysis of the deformation heating of the workpiece is one of the important factors in the study of especially SPD processes using large strains in order to form a high-strength state and an increased level of physical and mechanical properties. In this regard, for the process of free torsion, an analysis of temperature fields was carried out (Fig. 4). It has been established that in the process of torsion deformation, the temperature rises to $730^{\circ} \mathrm{C}$ in the region of strain localization, at lower values up to $500-520^{\circ} \mathrm{C}$ in the places where the workpieces are gripped. For steel 10 , a temperature of $700^{\circ} \mathrm{C}$ is on the verge of a recrystallization threshold; therefore, its excess is undesirable during free-torsion deformation.

Thus, with free torsion, a gradient temperature field in the range from 500 to $730^{\circ} \mathrm{C}$, initiated by deformation heating, is formed over the volume of the deformed sample. The results obtained show that when using the SPD, deformation heating is very significant [20] and both the time and temperature factors must be taken into account to ensure effective structure refinement.

\subsubsection{Microstructure investigation}

The Deform 3D software package is equipped with a unit for calculating the structure transformation during deformation. With its help, data were obtained on structural changes in the deformation zone, which are presented in Fig. 5. The data show that in more deformed areas of the workpiece, a finer structure is also formed, for example, in peripheral areas where the grain size, according to the assessment of these patterns, is about one micron. At the center of the deformation zone, the grain size is about $4-8$ microns. From the presented results it is seen that in the process of free

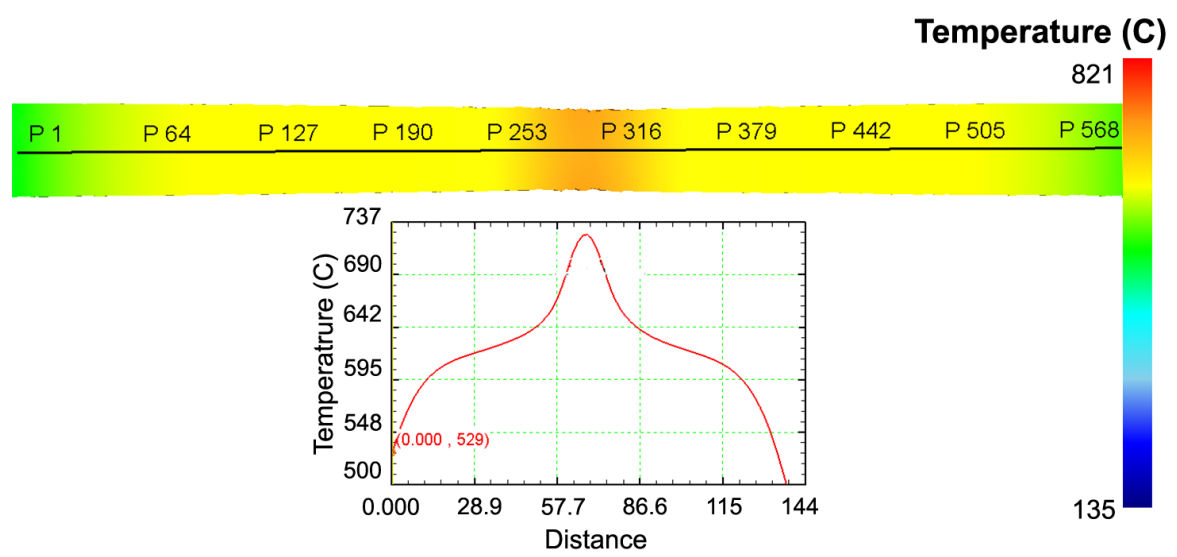

Fig. 4. (Color online) Picture and graph of the temperature distribution in the longitudinal section of the workpiece. 


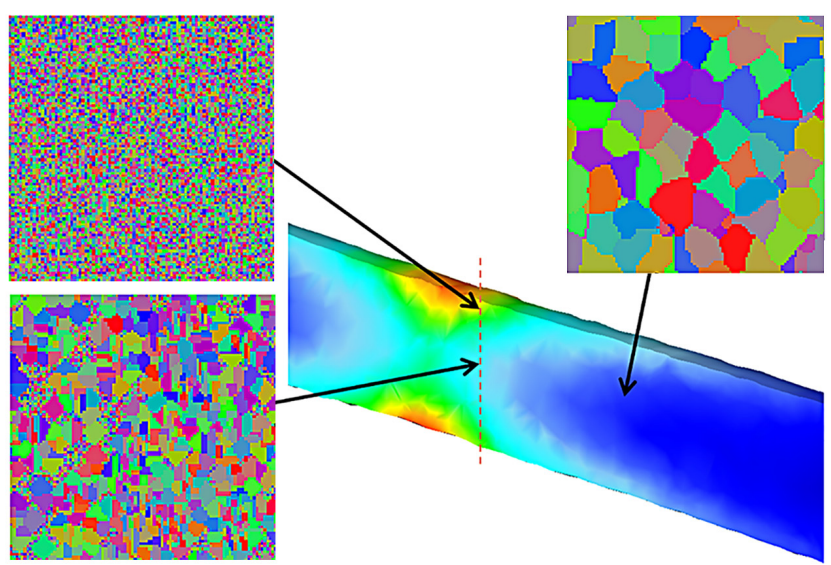

Fig. 5. (Color online) The pattern of structural changes in the localized deformation zone obtained by simulation.

torsion of the rod, substantial refinement of the structure occurs. On the other hand, according to the data obtained, it is rather difficult to quantify the size of structural elements, and rather, according to the results of the study, one should talk about getting a better picture of structural changes.

A cross section of the sample shows a microstructure gradient with a grain size from $1 \mu \mathrm{m}$ in the surface region of the deformed workpiece to $8 \mu \mathrm{m}$ closer to the axial region of the deformation zone. From the presented results it is seen that in the process of free torsion, substantial refinement of the microstructure occurs.

\subsection{Physical experiment}

As a result of experimental work, experimental samples were obtained after free torsion at $600^{\circ} \mathrm{C}$. The deformed state of the samples was evaluated by Eq. (1) used in the analysis of the deformed state of torsion processes using the intensity of shear strain $\lambda$. The kinetics of changes in the strain intensity depending on the number of revolutions is presented in the graph of the deformed state and is shown in Fig. 6.

$$
\lambda=\operatorname{tg} \varphi
$$

where $\lambda-$ is the shear strain intensity, $\varphi-$ is the maximum twist angle of the sample.

It should be noted that the value $-\lambda$, calculated by the formula (1), characterizes the intensity of accumulated strain directly at the surface layer of the rods. The data obtained by the analytical method differ from the data obtained by computer simulation.

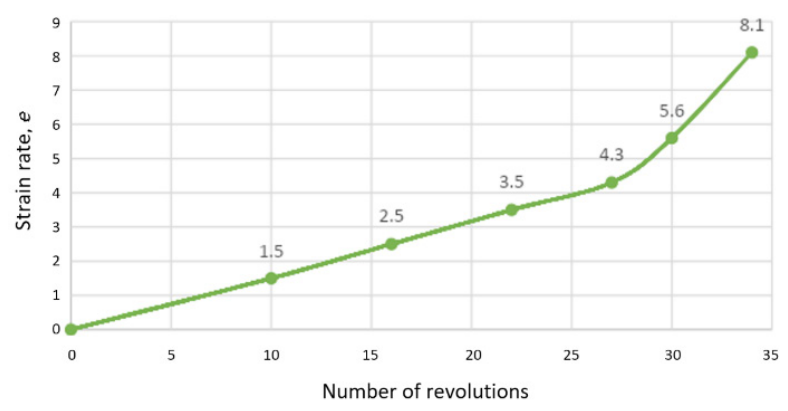

Fig. 6. Dependence of the strain intensity on the number of revolutions.
The test samples for measuring microhardness and microstructural analysis by light microscopy were cut from the obtained experimental samples. The geometry of the samples is shown in Fig. 7.

\subsubsection{Study of mechanical properties}

To study the mechanical properties of samples after torsion, the Vickers method was used to measure microhardness. The microhardness HV was measured by the diameter of the transverse direction of the rods in three regions of the workpiece according to the diagram shown in Fig. 8.

According to the results ofmicrohardness measurements, the graphs are presented for various sections along the length of the deformable bar, as can be seen from the graphs with an increase in the strain intensity, the maximum values of microhardness are observed in section 1 , where the microhardness in the nearsurface region reaches values over $200 \mathrm{HV}$, while in the central region the values reach about $125 \mathrm{HV}$, and in section 3 closer to the workpiece fixation, an increase in microhardness is also observed but not intensive enough, which indicates a gradient of mechanical properties both in the diametrical section of the sample and in the length of the deformed rod in the nearsurface region, while the microhardness practically does not change in the axial zone of the sample.

Also, to study the mechanical characteristics of deformable samples, tensile tests of standard samples were performed (Fig. 9). According to the results of these tests, tension curves were obtained in the initial state and after deformation by free torsion. It can be seen that the samples taken from the zone of maximum strain, closer to the fracture zone, show a significant increase in the strength of the sample up to $20 \%$ compared with the initial state. It should be noted that when testing the samples located at a distance of $35-40 \mathrm{~mm}$ from

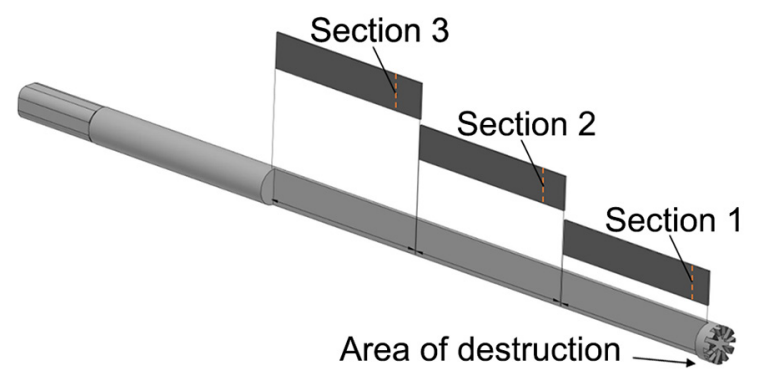

Fig. 7. Scheme of samples cutting for analysis of microstructure and microhardness after free torsion.

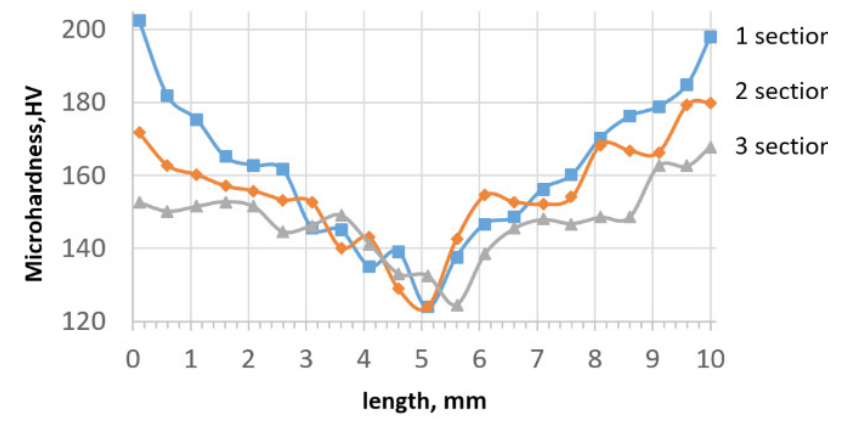

Fig. 8. (Color online) Microhardness over the cross section of a workpiece. 


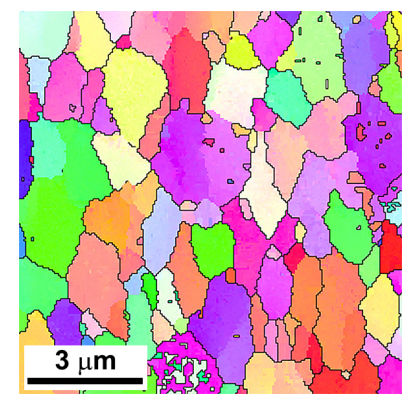

a

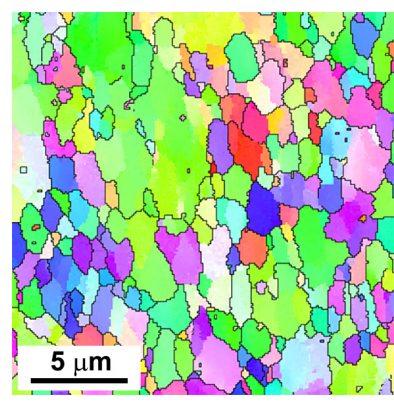

b

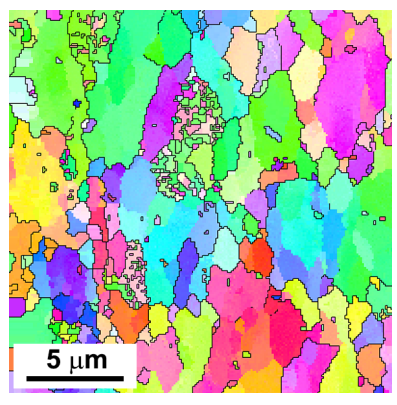

c

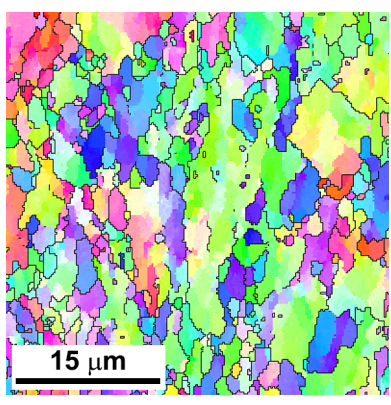

$\mathrm{d}$

Fig. 9. (Color online) IPF of samples after torsional deformation: near-surface region (a, b), axial region (c, d).

the fracture zone, the strength decreases and is also higher than the initial values by at least $10 \%$.

\subsubsection{EBSD analysis}

When studying the strain effect of the free torsion method on the microstructure of the material, EBSD analysis of samples obtained after deformation was performed. According to the results of the analysis, patterns of changes in the morphology of the microstructure are obtained. The obtained pictures (Fig. 9) illustrate the microstructure of the deformed material in the near-surface region (Fig. 9a,b) and the axial region (Fig. $9 \mathrm{c}, \mathrm{d}$ ) of the cross section of the workpiece. An analysis of the data presented shows the magnitude and degree of uniformity of the orientations of the boundaries of the formed grains after free torsion. For example, for the surface layer of the sample (Fig. 9 a, b), a random distribution of grain orientations after deformation is specific, which is much larger than in the axial region (Fig. $9 \mathrm{c}, \mathrm{d}$ ). The grain size reaches up to $0.6 \mu \mathrm{m}$.

\subsubsection{Investigation of the microstructural state}

Investigation of structural states revealed a number of features in the deformed sample (Fig. 10). So, under free torsion for accumulated strain $e>4.5$, the maximum grain refinement is observed in the peripheral layers of the workpiece. In this case, the average size of structural fragments is $2 \pm 1 \mu \mathrm{m}$. No structural defects in the form of pores are observed.

It was established that the formed type of structure has a gradient character, and the size of the structural elements varies from the center to the periphery in the range from $\sim 15$ to $\sim 1 \mu \mathrm{m}$. At the center of the localized deformation zone, grains $\sim 5 \mu \mathrm{m}$ in size are formed. One should note the correlation of the results with the results of the computer simulation.

\section{Conclusions}

1. Free torsion of cylindrical billets of steel 10 with a diameter in the longitudinal and transverse sections leads to formation of the gradient type microstructure in the direction of the peripheral regions of the billets with grain sizes from $\sim 50 \mu \mathrm{m}$ in the center to $\sim 1 \mu \mathrm{m}$.

2. The intensity of shear strain in free torsion has a gradient character, in the peripheral layers up to $e=8$. According to the results of computer simulation, a gradient distribution of the intensity of the accumulated strain with $e=5.9$ and $e=2.69$ is also noted.

3. The studies of the mechanical properties of samples, using the $\mathrm{HV}$ microhardness measurements, reflect the nature of the distribution of accumulated strain and are also

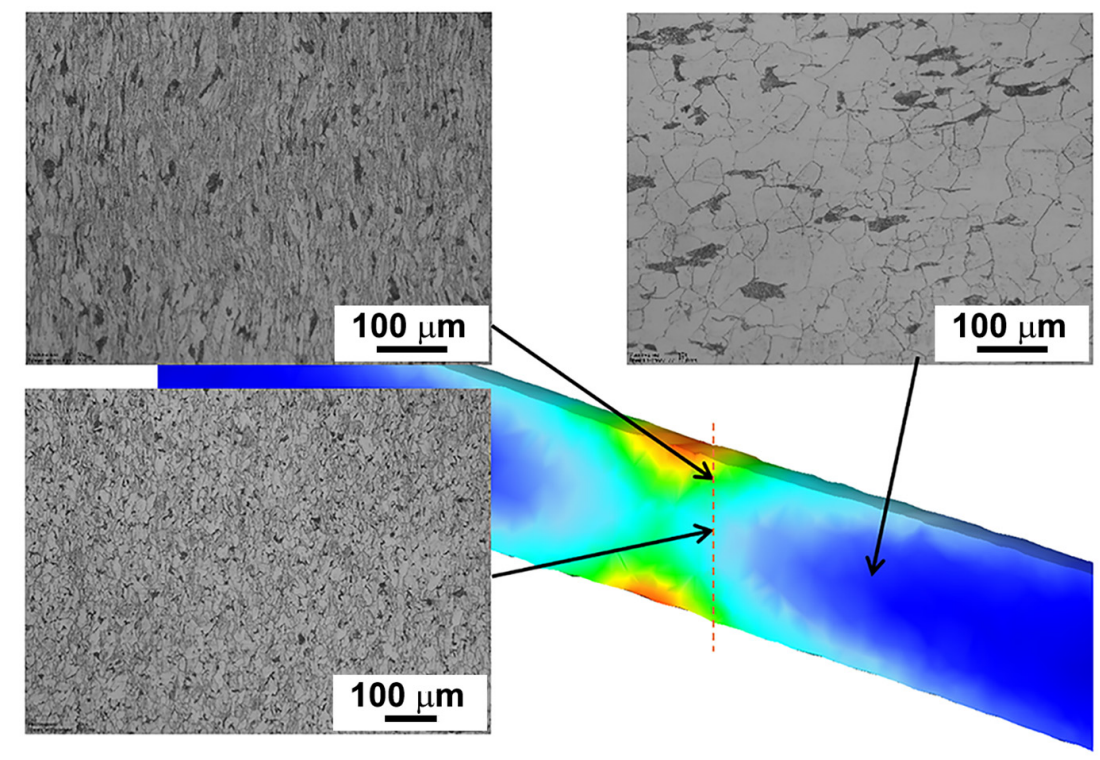

Fig. 10. (Color online) Structural states of preforms obtained by the method offree torsion (OM). 
gradient in nature, with maximum values of up to $200 \mathrm{HV}$ at the periphery and $125 \mathrm{HV}$ in the central region.

4. Under the conditions of deformation localization, intense deformation heating of the workpiece is observed, and the difference with the main thermal field is $230^{\circ} \mathrm{C}$.

5. The EBSD analysis shows gradient structure of steel specimens with a mean grain size of about $1 \mu \mathrm{m}$ near the surface region and $\sim 5 \mu \mathrm{m}$ near the central region.

Acknowledgements. The study was financially supported by Ministry of Science and Higher Education of the Russian Federation within the framework of the implementation of the Resolution of the Government of the Russian Federation of April 9, 2010 No. 220 (Contract No. 074-02-2018-329 from May 16, 2018). The work chapter 3.1.1, 3.1.2 and 3.1.3 performed of G.I. Raab and A. G. Raab is supported by the Russian Science Foundation under grant № 19-19-00432 and performed in Ufa State Aviation Technical University.

\section{References}

1. A.P. Zhilyaev, T.G. Langdon. Prog. Mater. Sci. 53, 893 (2008). Crossref

2. R.Z. Valiev, T.G. Langdon. Prog. Mater. Sci. 51, 881 (2006). Crossref

3. R.Z. Valiev, A.P. Zhilyaev, T.G. Langdon. Obyemnyye nanostrukturnyye materialy: fundamental'nyye osnovy i primeneniye. St. Petersburg, Eco-Vector (2017) 480 p. (in Russian)

4. V.M. Segal, V.I. Reznikov, A.E. Dobryshevshiy, V. I. Kopylov. Russian metallurgy (Metally). 1, 99 (1981).

5. F.Z. Utyashev, G.I. Raab. Deformatsionnyye metody polucheniya i obrabotki ul'tramelkozernistykh i nanostrukturnykh materialov. Ufa, Gilem (2013) 376 p. (in Russian)

6. G.A. Salishchev, O.R. Valiakhmetov, R.M. Galeyev. J. Mater. Sci. 28, 2898 (1993). $\underline{\text { Crossref }}$
7. S.V. Dobatkin, X. Sauvage. Volumetric nanostructured multiphase ferrous and non-ferrous alloys. In: Volumetric nanostructured materials (ed. by M.D. Tsekhetbauer, Yu.T. Zhu). Weinheim, WILEY-VCH Verlag GmbH \& Co. (2009) pp. 571-603.

8. A.M. Glezer, E.A. Levashov, M.Yu. Koroleva. Konstruktsionnyye nanomaterialy (study guide). Moscow, MISiS (2011) 176 p. (in Russian)

9. A.I. Rudskoy. Nanotekhnologii v metallurgii. St. Petersburg, Nauka (2007) 185 p. (in Russian)

10. G. I. Raab, A. G. Raab, V. G. Shibakov. Metallurgy. 54 (2) 423 (2015).

11. U.M. Lakhtin. Osnovy vybora materialov i uprochnyayushchey tekhnologii. Konstruktsionnyye stali: Textbook. Moscow, MADI (1993) 80 p. (in Russian)

12. G.I. Raab, A.G. Raab. Patent 2347632 RF. 2009. (in Russian)

13. A. G. Raab, M. V. Chukin. IV All-Russian Conference on Nanomaterials: collection of articles mat. Moscow, IMET RAS (2011) p. 43. (in Russian)

14. M.V. Karavaeva, M.M. Abramova, N.A. Enikeev, G. I. Raab, R. Z. Valiev. Letters on materials. 7, 29 (2017). (in Russian) Crossref

15. A. P. Zhilyaev. Letters on materials. 5, 276 (2015). Crossref

16. R.M. Imayev, A.A. Nazarov, R.R. Mulyukov, G.F. Khasanova. Letters on materials. 4, 295 (2014). Crossref

17. A.G. Raab, G.I. Raab, V.I. Semenov, G.N. Aleshin, U.N. Podrezov, N.I. Danilenko. Forging and Stamping Production. Material Working by Pressure. 12, 14 (2013). (in Russian)

18. https://www.deform.com/products/deform-3d/

19. V.N. Danilenko, S.Y. Mironov, A.N. Belyakov, A. P. Zhilyaev. Industrial Laboratory. 78, 28 (2012). (in Russian)

20. A.P. Zhilyaev. Letters on Materials. 9, 142 (2019). (in Russian) Crossref 